\title{
An Update on Curb Guided Bus Technology and Deployment Trends
}

\author{
David Phillips \\ TranSystems Corporation
}

\begin{abstract}
The first Curb Guided Bus (CGB) route opened in 1980. Although initial introduction of this technology was slow, six routes have opened since 1998, and more are in the works, mostly in the U.K. This paper presents a comprehensive review of the technology and its deployment.

\section{Introduction}

The author has been a key participant in two Alternative Analyses where the available right-of-way width was very restricted. To keep Bus Rapid Transit (BRT) as an option, some form of guidance would be required to ensure that buses could operate reliably in a very narrow lane. A literature search identified several guided bus technologies, but all were, and still are, in the research and development phase. The exception was Curb Guided Bus (CGB). However, little information was provided. This is a report on the author's extensive research on system design and operation for this technology, including site visits to most of the systems in operation. These visits included meetings with people involved in the initial technology research, system design, funding, operation, and maintenance of the infrastructure and the vehicles. It has been confirmed that this technology is appropriate in situations where even a limited amount of right-of-way is available and that
\end{abstract}


it can be installed with low risk. This ability to operate in narrow rights-of-way is especially important in constricted environments such as medians of arterial streets or freeways, on an abandoned railroad alignment or alongside an active railroad, on bridges or elevated structures, in tunnels, or under buildings. These narrow rights-of-way can make it possible to create dedicated transit lanes where otherwise none would fit. In addition, it was found that there are more advantages to the use of CGB technology, compared to either conventional, manually-steered BRT and other guided bus technologies, than simply the narrower right-of-way configurations.

\section{Figure 1. Curb Guided Bus, Adelaide}

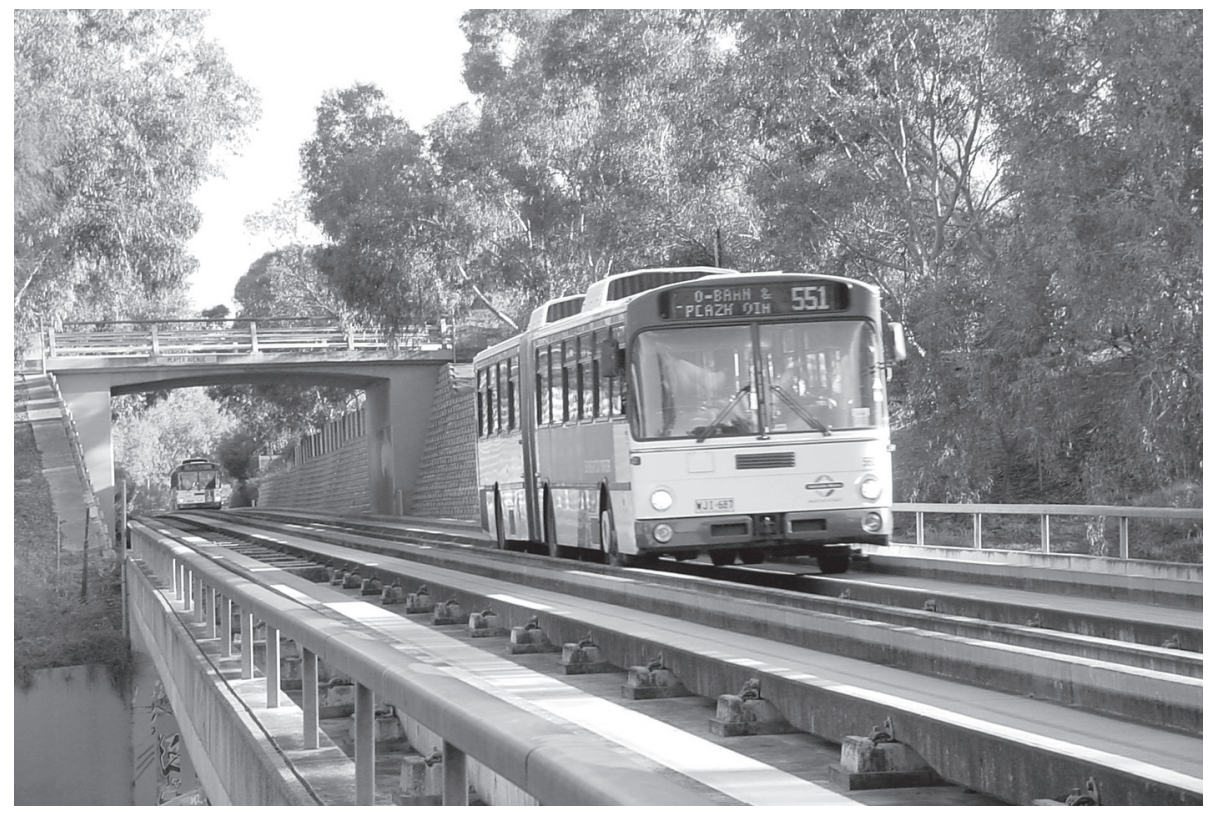

Source: TranSystems

\section{Curb Guided Bus Sytem Operations}

A major surprise in the research was the number of CGB systems in operation. None of the previous guidance technology articles had mentioned more than two or three routes. There are, in fact, 12 systems in operation, and two other well- 
advanced future systems. Site visits were made to most of them. Table 1 lists these Systems, in the order of their opening date. Table 2 lists future systems.

\section{Table 1. Curb Guided Bus Systems in Operation}

\section{0 - Essen, Germany}

Fulerumer Strasse - All of the system's routes started under a government demonstration program. EVAG now operates a 3 route system with 3.7 miles of bi-directional guideway in 3 separate segments. All were previously private right-of-way portions of streetcar routes. The first segment operates in a parklike setting that demonstrated operation through grade crossings and on a $6 \%$ grade.

\section{3 - Essen, Germany}

Wittenbergstrasse - This section was the test site for joint operation of dual mode buses with streetcars. Concrete and wood running surfaces were tested. Following the test, a section in tunnel, shared with streetcars, was operated for 11 years. Only guided buses operate in Wittenbergstrasse now.

\section{6 - Adelaide, Australia}

Operates the world's fastest guided busway, a 7.5 mile long line operated at $100 \mathrm{~km} / \mathrm{hr}$ (62 $\mathrm{mph}$ ). The "O-Bahn" was opened in two segments, in 1986 and 1989. The two intermediate stations are designed for passing. One-minute headways are operated in the peak hour.

\section{6 - Essen, Germany}

A40 Motorway - This section includes the sharpest guided busway curves (60 m, about 190 ft., radius), which requires the Essen buses uniquely to be equipped with guidewheels at each axle. It also has a ramp on structure with a $6 \%$ grade. All Essen routes were built with pre-cast concrete guideway sections, which still provide a very smooth ride. Essen expects to award a contract for a new generation of guided buses (its fourth) shortly.

\section{5 - Ipswich (Kesgrave), U.K.}

This guided busway is only about $600 \mathrm{ft}$. long, and is operated as part of the "Super Route 66" between Ipswich and Martlesham Heath. The guided busway segment is provided to ensure that only buses use the roadway, which provides a shortcut bypassing congested intersections.

\section{8 - Leeds, U.K.}

A61 Scott Hall Road Corridor - North of Central Leeds (includes a total of one mile of guided busway) this consists of single-direction busways located alongside parallel roads, "queue jumpers" (which provide priority access to roundabouts), a contraflow non-guided lane for the entry into the center city, and signal priority. This corridor includes a section on a $7 \%$ downgrade, the steepest CGB operation. Ridership on the routes that benefit from the facilities provided in these corridors has exceeded the performance of buses as a whole in Leeds. 


\section{0 - Nagoya, Japan}

The Nagoya Guideway bus (also known as the Yutorito Line) is a 4-mile-long guideway installed on a structure to separate buses from regular traffic. There are 9 stations on the guideway structure. At Obata-Ryokuchi station, buses descend a ramp and continue in mixed traffic on regular surface roads to serve Nagoya suburbs. Despite the short vehicle length, guidewheels are fitted both at the front and behind the rear axle due to sharp curvature. Operations are managed as a third-sector company, and the cost of building the elevated guideway infrastructure was borne by the Nagoya City roads budget.

\section{1 - Leeds, U.K.}

York/Selby Roads "Elite" Project - East of Central Leeds (1.3 miles of guided busway), this is served by buses of two different private operators, who paid a significant share of the project's construction cost. It was the first built using slipform concrete construction. The only section of bi-directional guideway in Leeds is included.

\section{2 - Bradford, U.K.}

The Manchester Road project (1.4 miles of guided busway) located south of central Bradford (itself about 10 miles west of central Leeds) is the newest busway in the Leeds-Bradford area. The guided sections are all in the center of the roadway, with signal priority for buses entering them from the curbside. It includes shelters that are intended as artwork.

\section{3 - Sussex, U.K.}

Two sections of guided busway were provided as part of Route 10 of the "Fastway" network of high quality bus services being established in this area south of London. This is currently the only guided busway project in which a dedicated fleet of buses, in distinctive colors and more stylish than the norm for the operator's standard buses, is employed. Other Fastway components include high quality passenger shelters with real-time information and signal priority.

\section{4 - Edinburgh, U.K.}

"Fastlink" is a 0.9-mile-long, bi-directional guided busway installed as part of Edinburgh Translink's program for transit improvements. The guideway includes two overpasses built to bypass complex intersections and roundabouts.

\section{6 - Sussex, U.K.}

The most recent section of guideway is for the Fastway system's Route 20. 


\section{Table 2. Future Systems}

\section{8 - Cambridge-St. Ives, U.K.}

This is expected be the longest guided busway system, consisting of 11 miles of guideway to be built on an abandoned rail line. The national government has committed to funding. The county is currently considering design/build proposals for this project, which is estimated to cost about $\$ 60 \mathrm{M}$, at current exchange rates.

\section{9 - Luton, U.K.}

This will consist of 8 miles of guideway, also to be built on an abandoned rail line. The public consultation process has been completed, and a government funding decision is expected shortly.

\section{Figure 2. Sussex, U.K., Fastway Bus}

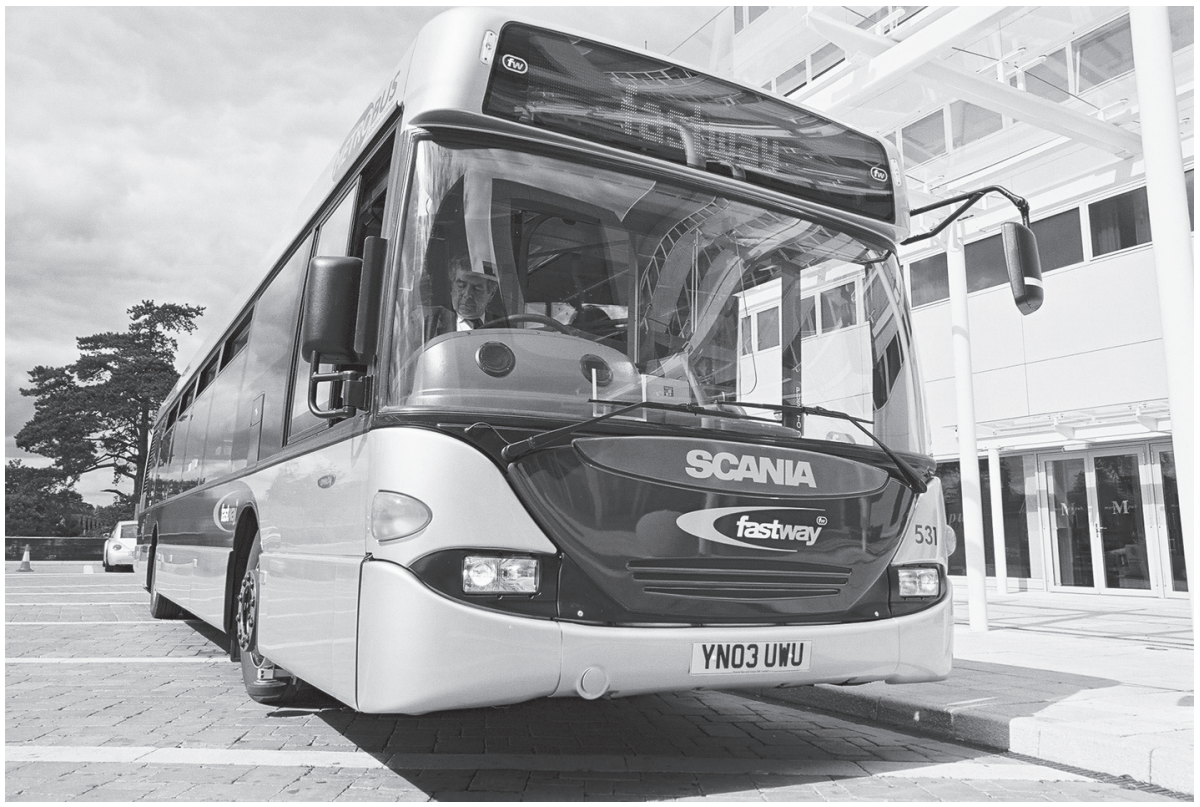

Source: Stevens Associates

Note: Sussex, U.K., Fastway Bus system combines stylish buses and shelters and real-time information at stops, with segments of guided and conventional busway to provide high quality service. System was completed in 2006. 


\section{CGB Infrastructure and Vehicles}

CGB technology itself is simple, non-electronic, and non-proprietary. The guideway consists of concrete running surfaces with vertical curbs about eight inches high. On all systems, the curbs are set 2.6 meters (102.4 in.) apart, being designed for the 2.55 meter (100.4 in.) wide buses that are standard outside North America. A bi-directional guideway, suitable for high speed operation with 102 inch wide North American buses, can be constructed in a right-of-way of less than 25 feet in width, including an emergency walkway on each side. The alignment of a lane constructed on an at-grade route would require only about a 10-foot right-of-way. This is much narrower than conventional busways designed for manually-steered buses.

In addition to at-grade alignments, CGB technology has been applied to routes in subways. The ability of CGB systems to operate safely at speed in narrow rights-ofway is particularly important in these cases, where minimizing the required width can greatly reduce the cost of constructing tunnels. Essen operated dual mode buses in tunnels for 11 years. It was particularly interesting that these tunnels and subway stations were shared with streetcars. Full block signaling was provided. Unfortunately, the pre-existing streetcar trackage used wooden ties on ballast construction. The bus trackways installed expeditiously as part of the demonstration project were also wood, bolted to the ties. Over time, the ties and trackways deteriorated. The operator did not have the resources available to install a concrete trackbed, as a new system designed for combined operation would be. The buses were removed, returning to their former surface street operation. A new system intended for combined operation could be built with rails embedded in the bus trackways. Essentially, this would be standard streetcar/LRT in-street track with the addition of curbs. Of course, a subway could be built for use only by CGB vehicles.

The same applies on bridges and elevated structures. The Nagoya, Japan, system operates on a four-mile-long guideway that is located entirely on an elevated structure located in an area of the city with heavy traffic congestion. Bus routes fan out on regular streets when they reach the end of the guideway. There are nine stations on the guideway, including the railroad interchange station. CGB technology was selected because of the narrower, lower cost structure requirements and the faster operation that can be permitted compared to a conventional busway.

The system is based on research funded by the German government in the early 1980s. There are no license fees involved. Anyone can build a roadway with curbs. 
A comprehensive handbook for design of CGB infrastructure, based on the experience of the practitioners in the field, was issued in 2004. Systems around the world utilize the same design for the "funnel" used at the entrance to guideways (see Figure 1). The speed limit for the funnel is typically set at $25 \mathrm{mph}$. Where it is necessary to allow pedestrians or other traffic to cross a guideway, the curbs can be gapped. Short gaps (less than 10 feet) can simply be crossed (at $30 \mathrm{mph}$ ). Longer gaps require a re-entry funnel. The handbook provides guidance on a wide variety of other design details.

\section{Figure 3. Typical Section of CGB Guideway, Showing Potential to Share with Streetcars}

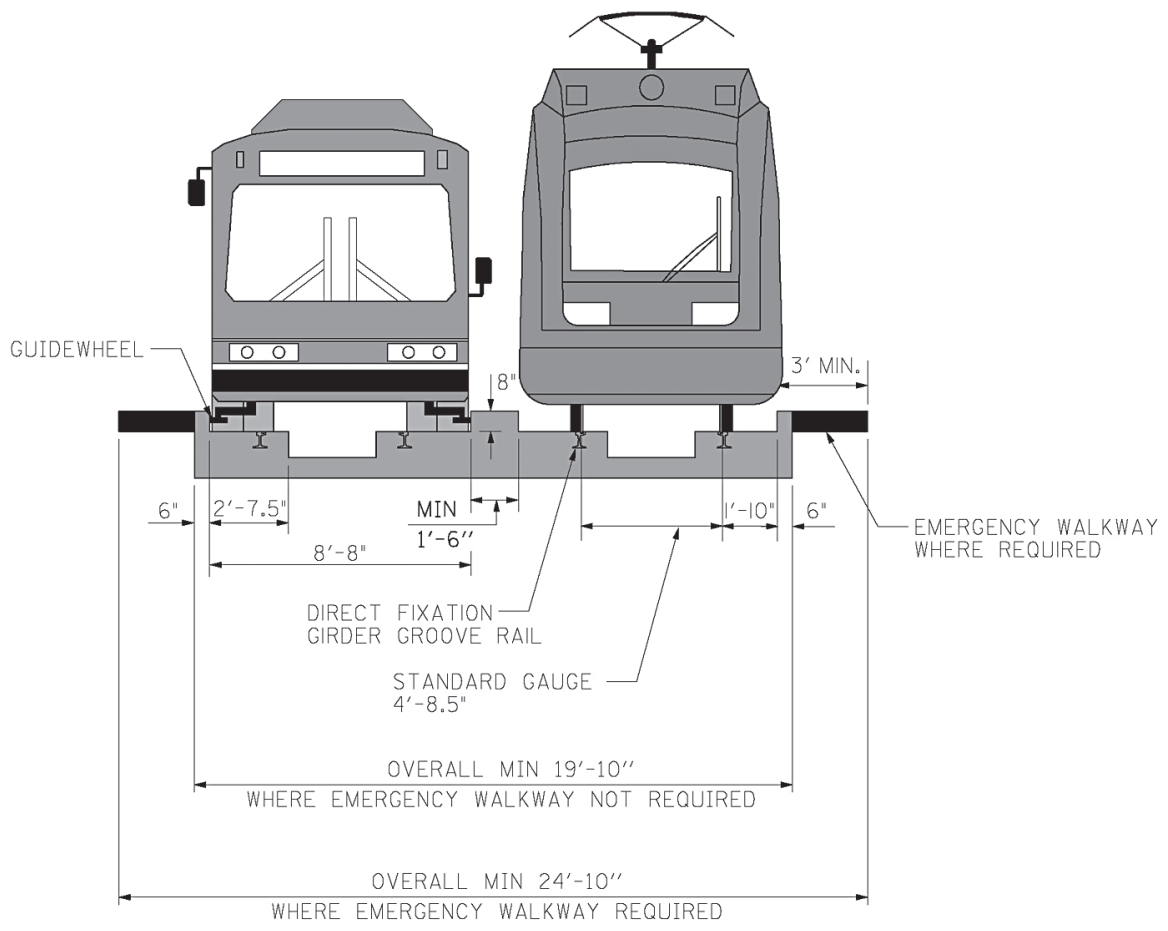

Source: TranSystems

Similarly, any bus manufacturer can design and build guidearms for its buses. While buses for CGB operation are, essentially, standard buses, the guidearms have always been designed by the bus manufacturer, with buses delivered complete 
with guidearms and guidewheels. CGB buses have been built by at least eight manufacturers worldwide. The first system in Essen, Germany, equipped its buses with guidewheels at each axle (virtually all of its buses have always been three-axle articulateds). All subsequent systems (except Nagoya, Japan) have used slightly less tight minimum curve radii, allowing their buses to be equipped with guidewheels only at the front axle, simplifying vehicle design issues. All systems use the same supplier for the horizontal guidewheels. After the design of the guidearm/ guidewheel for a particular bus type is complete, actual manufacture and installation cost is relatively minor. With the proliferation of CGB operation in the U.K., most new buses there are built ready for this installation.

All CGB systems currently in use are operated with diesel buses. Several systems have purchased buses with extra silencing packages, reducing noise inside and outside the vehicles. As noted above, Essen operated portions of its CGB system under electric overhead power wires for many years. This is an option for future routes. In the meantime, avoiding the cost of installation of an electric distribution system greatly reduces the cost of a new system compared to LRT and streetcars.

\section{Figure 4. CGB Guideway Entry Funnel, Adelaide}

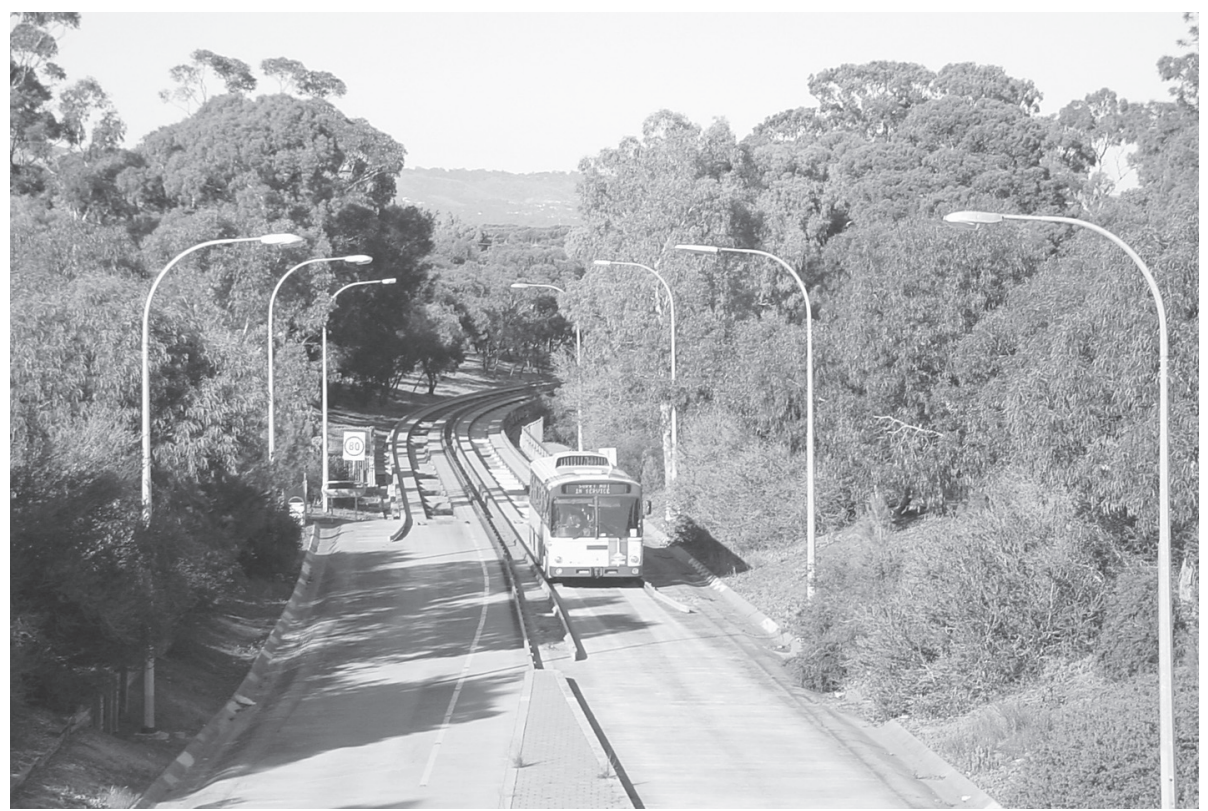

Source: TranSystems 


\section{Figure 5. Typical Guidearm/Guidewheel Installation- Mercedes Bus in Adelaide}

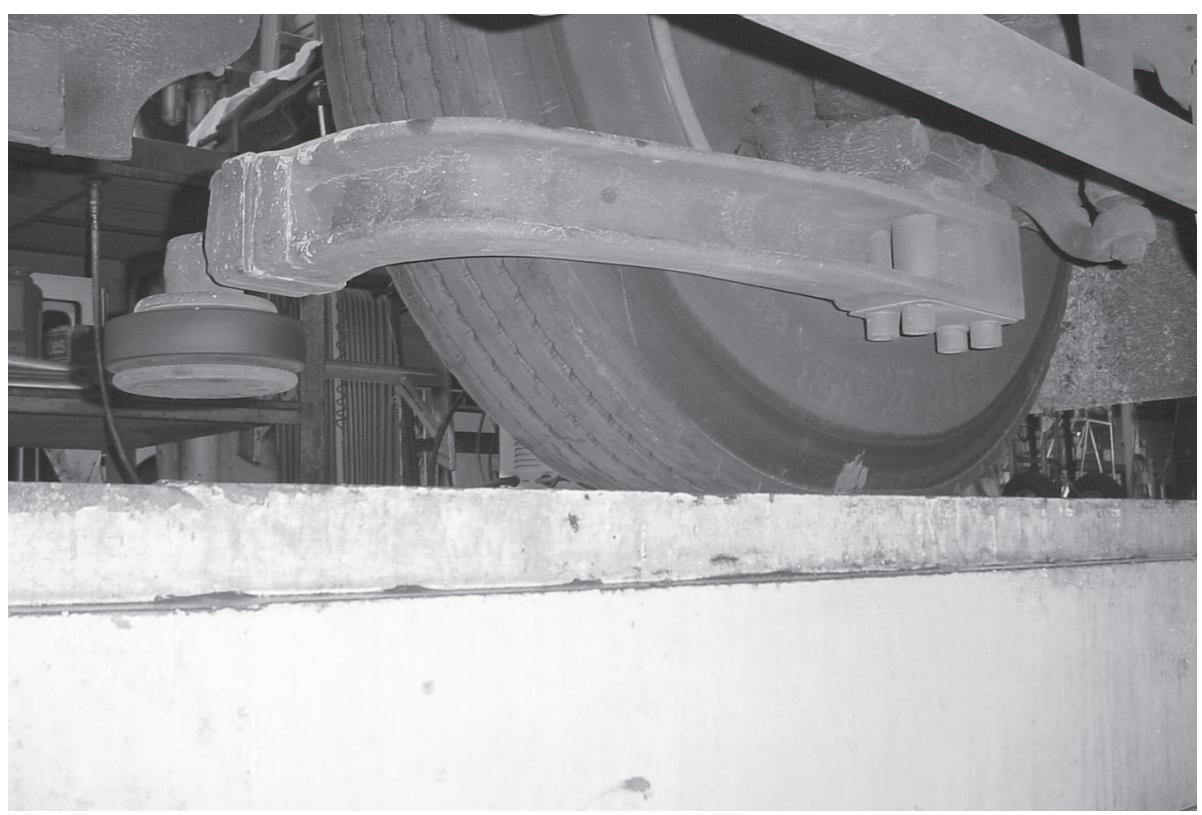

Source: TranSystems

\section{CGB System Operation}

A key advantage of CGB buses, compared to LRT and streetcars, is that that they can operate as standard buses when they are off the guideway. The guidewheels extend only about one inch beyond the body of the bus. All CGB routes combine guideway and normal on-street operations, avoiding the necessity for passengers to transfer from a feeder bus to another vehicle.

On most systems (notably Leeds, Bradford, Sussex-UK and Essen Fulerumer Strasse), guideways are provided only along street segments that regularly experience congestion, frequently only in one direction, further reducing right-of-way requirements. Transit signal priority is normally provided at the end of the guideway to facilitate the movement of the buses as they re-enter mixed traffic lanes. Speed limits on sections that run beside streets are normally set at the speed limit of the adjacent street. 
There are also long, high-speed systems. The best example of this type is the 7.5mile-long Adelaide O-Bahn. This route is fully grade separated and has only two intermediate stops. Because the guideway is so narrow, there was room to construct a beautiful linear park, with bicycle and walking paths along its entire length. The speed limit is set at $100 \mathrm{~km} / \mathrm{h}$ (62 mph), except where limited by curves.

\section{Figure 6. Paradise Interchange, Adelaide 0-Bahn}

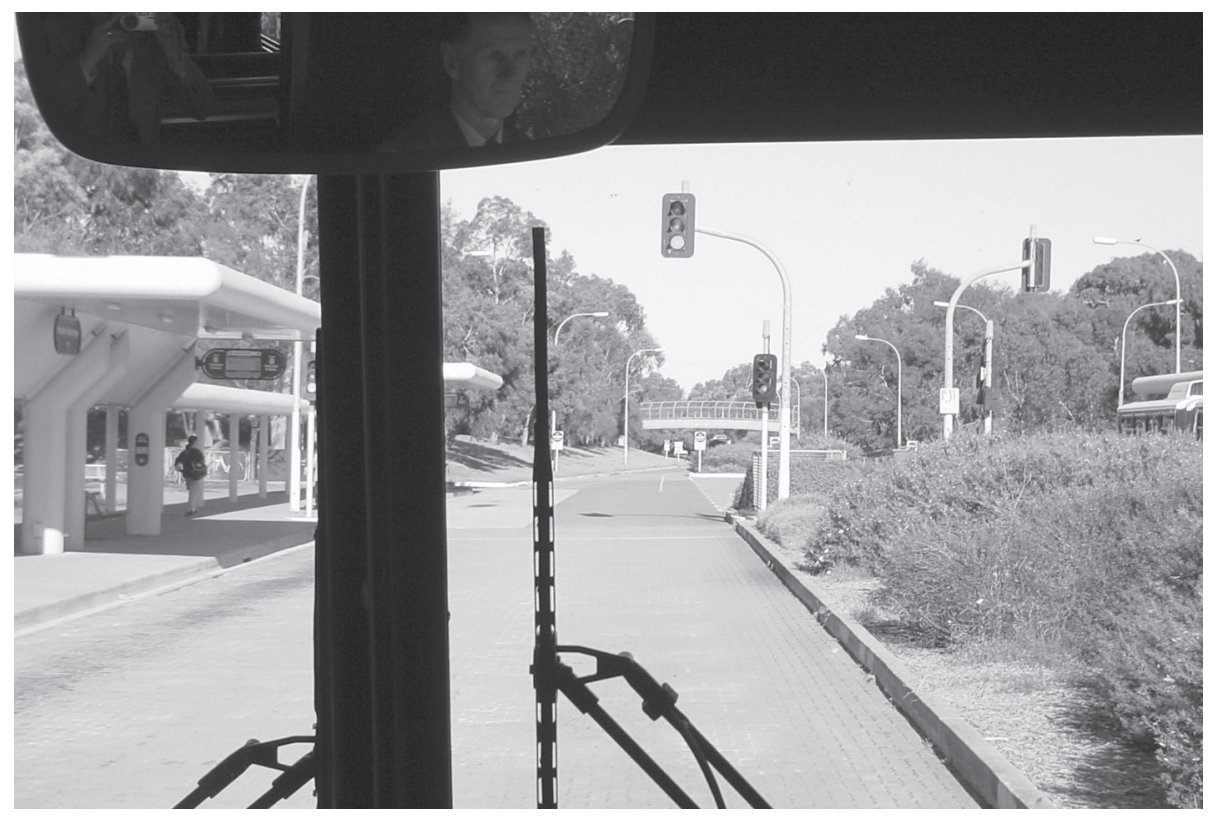

Source: TranSystems

At one of the intermediate stops, additional routes join the busway. It is expected that construction will start in early 2007 on the Cambridge-St. Ives system in the U.K., which will have a guideway 11 miles long, the world's longest guided busway. This is being procured as a design-build project.

A key advantage of CGB guideways is that they are completely self-enforcing. Unlike conventional bus lanes, non-guidewheel equipped vehicles cannot operate on them. Some sections of guideway have been installed specifically for this reason; they are shortcuts that can accommodate the relatively low volume of buses but that the authorities do not want open to general traffic. Examples include the 
entire Ipswich Guided busway, only 200 meters long, and some sections of the Sussex Fastway system.

\section{Figure 7. Subway in Essen, with Dual Mode Buses and Track Shared with Streetcars}

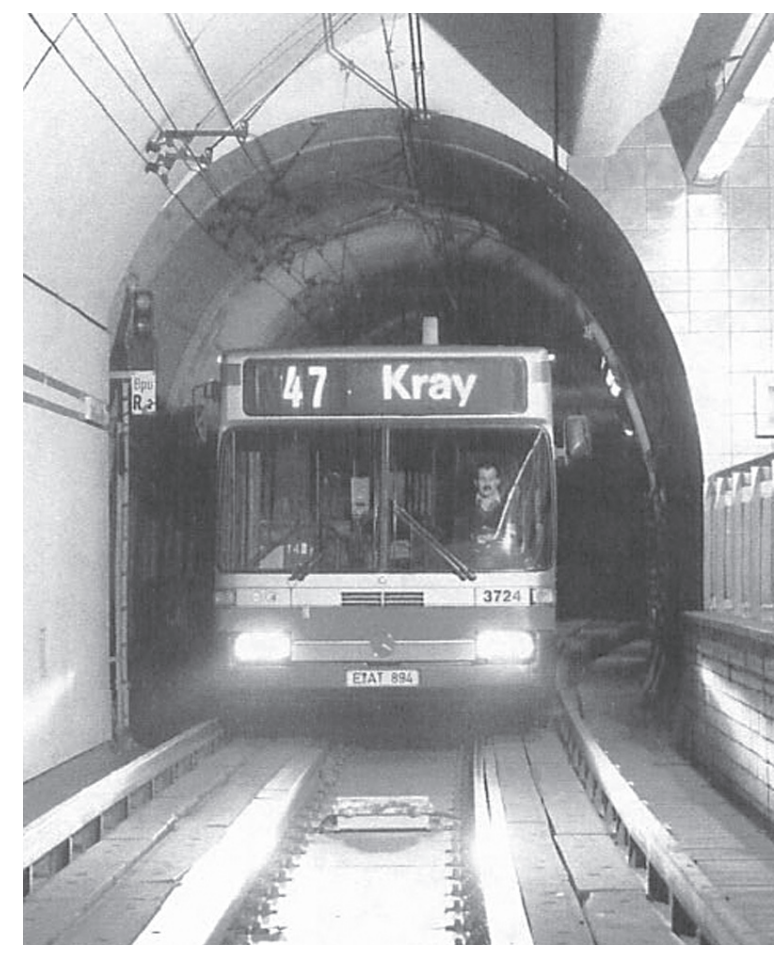

Source: EVAG

\section{Stations and Precision Docking}

CGB stops or stations vary from simple bus stops (usually with, at least, a simple factory-built shelter) to stations equal to sophisticated light rail stations, with full canopies, real-time passenger information, ticket vending machines, and park-andride lots. On most systems, stops made at intermediate stations are online; buses do not leave the guideway. All buses usually operate as locals, making all stops on request. However, on one of the Leeds busways and on the Bradford route, there 
are express bus routes to the suburbs that are not scheduled to stop at some bus stops. If they are behind a local bus that makes a stop, they wait briefly.

The two intermediate Adelaide O-Bahn stations are unique in that buses come out of guidance and the roadway widens, allowing express buses to pass, although few are scheduled. The Adelaide stations are the most expansive CGB stations, with long platforms and extensive canopies. The large park-and-ride lots are overflowing. Particularly during off-peak periods, feeder routes terminate at the O-Bahn stations, sharing a platform with through buses to/from downtown, allowing same platform transfers.

One of the principal justifications for implementation of guided bus operation is that it readily provides "precision docking" in the same way as a rail system. With the advent of low floor buses, full level boarding is provided. This allows meeting ADA accessibility requirements without deploying a lift or even, in many cases, a ramp. Even passengers on the older CGB systems, with platform heights that had been set to the level of the first step of conventional high floor buses, are now enjoying these benefits. When combined with off-board fare collection (typically, employed with proof-of-payment enforcement), passengers can board quickly, at any door.

The handling of stops for guided buses when operating off guideway has varied greatly. Because stops in Adelaide are offline, stations and street stops have low curbs. Leeds pioneered the use of raised boarding platforms at stops off the guideway. Operators are instructed to drive with the guidewheel against the curb. A section of raised curb is provided, resulting in level boarding. Such stops can only be served only by buses with guidewheels.

A new U.S. BRT system, the Euclid Corridor in Cleveland, will provide precision docking by installing guidewheels solely for this purpose on the buses being built for the route. Coincidentally, the corridor will have some center median stations, requiring left side doors to be installed. Thus, these will be the first buses in North America with guidewheels installed on both sides, although no guideway operation is currently planned.

In Leeds today, there has been a change in practice: all off-guideway bus stops are now being equipped with a partially sloped-curb, which allows all buses, with or without guidewheels, to be driven close to the curb at stops without damage due to contact with the curb to either the body or the tire sidewalls. This provides a narrow horizontal gap. Such curbs (off a guideway) are now being installed at a 
lower height, $180 \mathrm{~mm}$ (about 7 inches), since buses, when kneeled, are within 50 $\mathrm{mm}$ ( 2 inches) of the platform, the allowable vertical gap in the U.K. Thus, the sidewalk does not need to be raised significantly to serve as a platform.

In a similar way, Las Vegas is providing level boarding on its MAX system, with raised platforms and boarding permitted at all doors, using Proof of Payment enforcement of the off-board fare collection. It was planned to achieve precision docking on this system through the use of an optical guidance system. However, the system was unreliable and has been turned off since shortly after the start of service. Because the stations were equipped with sloped curbs, very similar to those in Leeds, it has been possible to continue to provide level boarding with satisfactory horizontal gaps with manual steering. This is facilitated by the lack of parking on the approaches to the stations.

\section{Figure 8. Level Boarding, Las Vegas MAX}

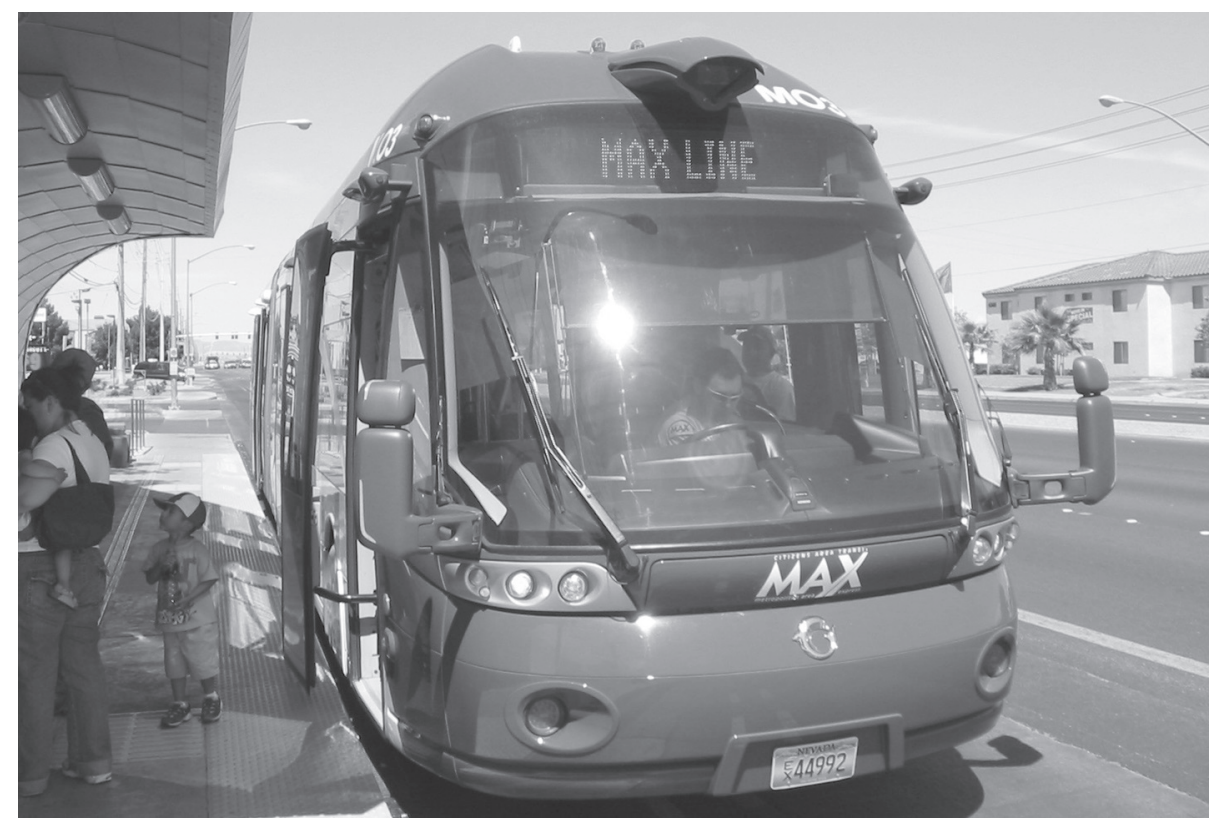

Source: TranSystems 


\section{Guideway Construction and Maintenance}

The first CGB route operated in revenue service was in Essen (1980). It uses the technique of precast segments mounted on "sleepers" (cross beams), mounted, in turn, on short drilled piles. Today, 26 years later, this line continues to provide an extremely smooth ride, and there is no structural deterioration of the concrete running surface or discernible wear. Subsequent sections of guideway in Essen were built using this technique, except for ramps, sharp curves and entries, which were poured in place. Since these sections are negotiated at lower speeds the slightly rougher surface is not noticeable. The Adelaide O-Bahn uses the same type of pre-cast guideway segments, built in Australia by the same manufacturer. However, due to the extremely silty soil along the alignment in the Torrens River Valley, each sleeper rests on two 3 meter (10 feet) deep piles. This technique has prevented any problem with settlement and provides very good ride quality.

\section{Figure 9. Precast Concrete Construction}

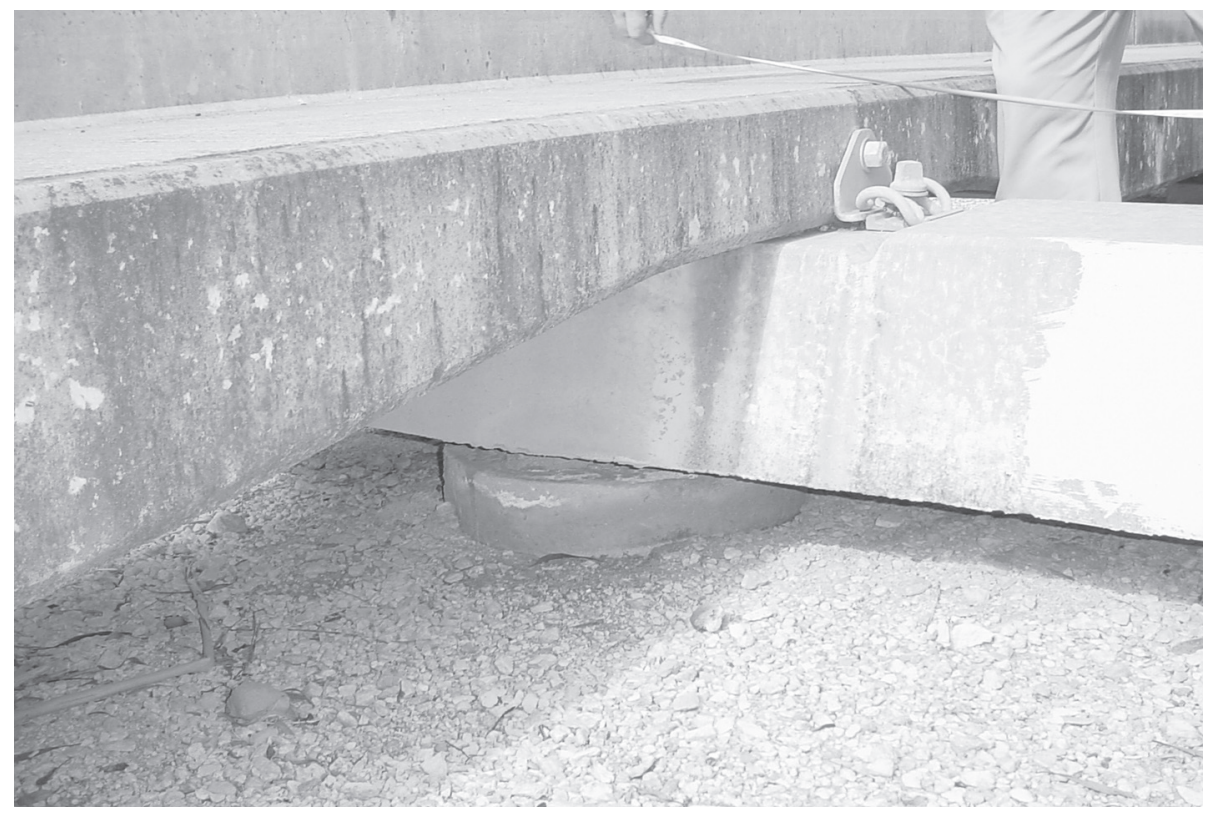

Source: TranSystems 
All of the U.K. systems use poured in place concrete. The early ones were constructed using conventional practice. A major innovation has been the use of slipforming machines for all of the U.K. CGB projects since 2001. For the Sussex Fastway, the most recent CGB project, construction tolerances for width were held to $+3 \mathrm{~mm}$ ( 0.12 inch) - $0 \mathrm{~mm}$, with installation over a base of $300 \mathrm{~mm}$ (12 inches) of recycled concrete. This process has resulted in a smooth ride quality and is expected to have a long life. This project was constructed with paving equipment made by Gomaco, a major American supplier. Rebar baskets for each track can be assembled in a mass production environment and connected in the field. Typical roadway slipform paving production is about 2500 lane-feet per day. It should be noted that quality control on the Edinburgh Fastway was inadequate, with the result that ride quality was substandard until corrective grinding was carried out by the contractor. Interestingly, drainage is greatly simplified compared to normal roadways because of the ability to leave the center strip unpaved. Overall construction cost should be essentially the same as construction of a normal roadway.

\section{Figure 10. Slipform Construction}

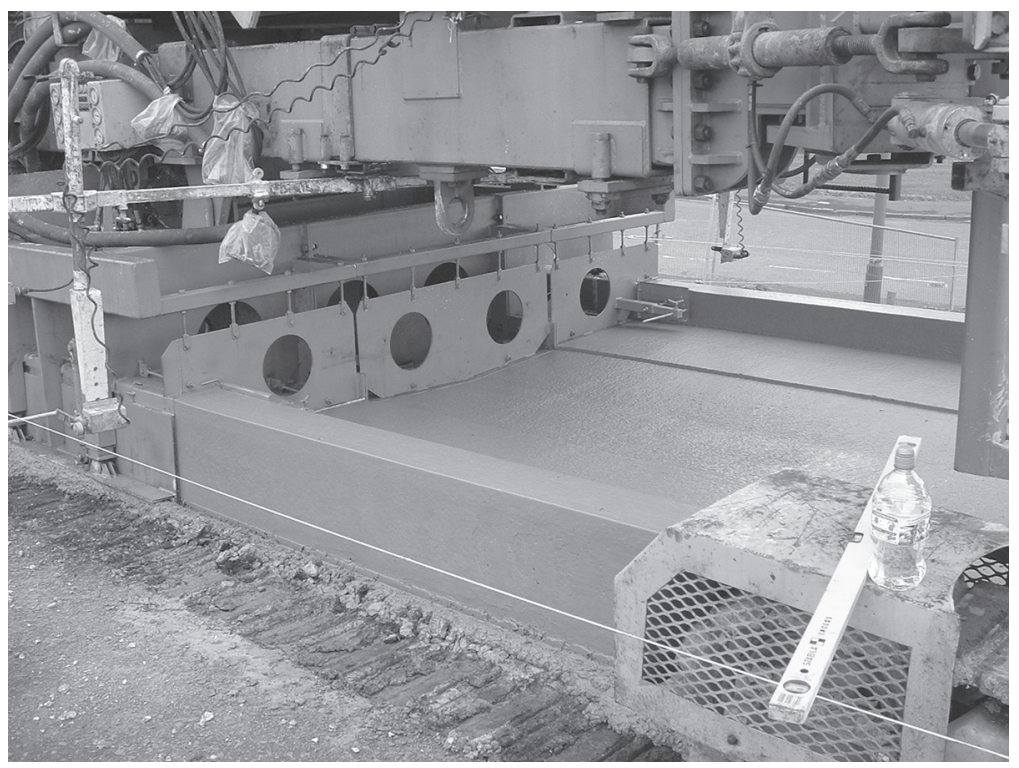

Source: British in-situ Paving Association 


\section{Special Considerations in CGB System Design and Operation}

While CGB technology is basically simple, there have been some adaptations over the years that are not immediately apparent. All systems provide specialized training and qualification procedures for CGB operators. One feature that is applied fairly universally is that "run-flat" rings are installed inside the front tires, allowing buses to continue to the first guideway exit point, at reduced speed, if air pressure is lost. Adelaide takes special precautions for its high speed operation. It has added an emergency button that operators must use if their bus is disabled to prevent rear end collisions. When activated, rotating yellow lights are started, and a prerecorded verbal "bus stopped" message is broadcast to all buses operating from the garage at which O-Bahn buses are based. All buses on the busway must stop until the originating operator is able to identify their location and direction.

There have been two pieces of specialized non-revenue vehicles constructed for CGB systems. Both have guidewheels on each end, allowing bi-directional operation. Adelaide has a recovery vehicle matched to its high-speed operation, with relatively long gaps between busway exits. It has cabs open both ends, facilitating rapid movement against the normal flow of traffic to reach the disabled bus. $A$ towbar and air brakes can be quickly connected. Essen has the equivalent of the Swiss Army knife: a multipurpose vehicle equipped with towbar and air brake connections on each end, a crane, a dump body (including a salt spreader insert), and a snow plow. Essen has significant snow/ice conditions and experienced serious problems at times in maintaining traction on the ramps prior to putting this vehicle into service. In most cases in Essen, disabled buses are simply pushed to the next guideway exit by the following bus. This solution may be facilitated by the multiple guidewheels on its buses.

\section{Curb Guided Bus Trends}

Installation of CGB routes has been slow. The Essen routes were constructed over a number of years as part of a demonstration program. Toward the end of this period, the Adelaide system was constructed, in two phases. The only new CGB operation that opened between 1989 (the completion of the Adelaide O-Bahn) and 1998 (opening of Scott Hall Road in Leeds) was the 600 foot long Kesgrave (U.K.) guideway. However, since then, about one new route per year has opened, and more are in the works. All of these, except the Nagoya system, are in the U.K. 


\section{Figure 11. Essen Multipurpose Truck}

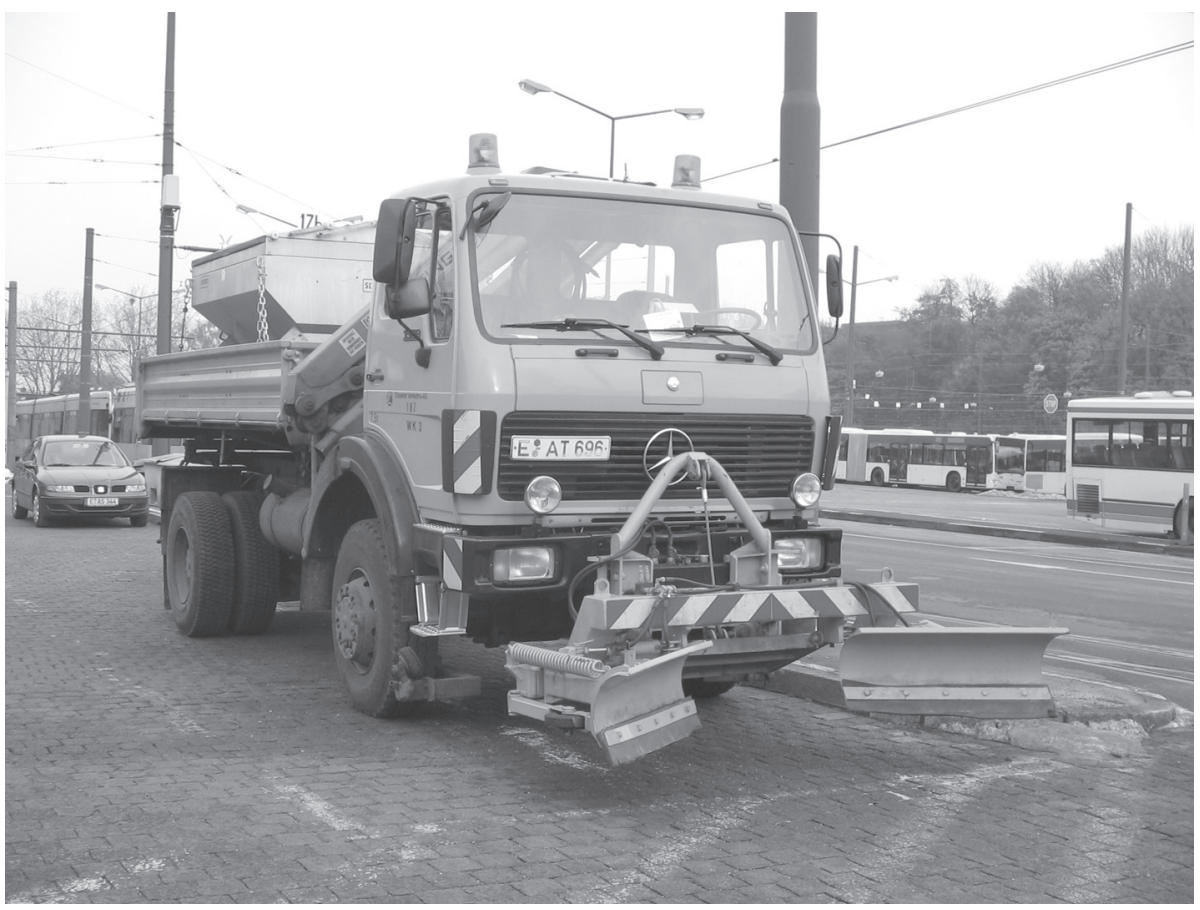

Source: TranSystems

CGB technology provides a means of providing BRT service with quality more like LRT, with fast operation and level boarding. It fits into rights-of-way where conventional BRT with dedicated lanes may not fit. It provides one-seat rides where LRT may require passengers to transfer to/from feeder buses. It can be implemented incrementally, starting in part of a corridor. Yet its installation cost is not significantly higher than conventional BRT and is significantly lower than LRT. With more awareness of this technology, its rate of growth, and geographical dispersion, may increase. 


\section{References}

Boegner, J., and M Starck. Undated. Guided bus essen, information on the research and development project. Essener Verkehrs-AG, Essen.

Bray, D.J. and D. Scrafton. 2000. The Adelaide O-Bahn: Ten years on. In 8th Joint Conference on Light Rail Proceedings (CD_ROM Paper K-31. pp1-16), Dallas.

Bray, D.J. 2000. The Performance of the Adelaide O-Bahn. In Smart Urban Transport Conference Proceedings, Brisbane.

Chapman, P.C. 1992. The Adelaide O-Bahn - How good in practice? Seventeenth Australasian Transport Research Forum Conference, Canberra.

Kim, E.J., G. Darido, and D. Schneck. 2005. Las Vegas MAX BRT Demonstration Project Evaluation, Federal Transit Administration, Washington. . 1999. Adelaide's O-Bahn Busway - Guiding transport into the future. Passenger Transport Board, Adelaide. 2004. Guided Busway Design Handbook. British in-situ Paving Association, Blackwater, Camberley, Surrey .2005. BRT lane assist technology systems. Metro Transit, Minneapolis.

\section{About the Author}

DAvid PhILlips (dphillips@transystems.com) has over 30 years of experience in all phases of transit operations planning projects including rail and bus operating plans, rail feeder bus networks, coordination with development, vehicle systems, real-time operational strategies, communications/vehicle location technology, and transit traffic signal priority. After 27 years at the Chicago Transit Authority (in Operations Planning and project management for technology projects), he moved to the private sector. At TranSystems, he has served as project manager for several major rail and bus infrastructure studies and design projects. 